\title{
“Eureka!" "That's funny...": Problematization and value in two classroom epiphanies
}

\author{
Gabriel S. Ehrlich ${ }^{1}$ and Mats A. Selen ${ }^{1}$ \\ ${ }^{1}$ Physics, University of Illinois at Urbana-Champaign, 1101 W. Green St., Urbana, IL, 61801
}

\begin{abstract}
Recent work in epistemic affect contends that students' affect during inquiry is entangled with their cognition. Epistemic affect affords a lens through which to uncover the etiology of epiphanies, in which a cognitive leap co-occurs with an expression of positive affect. Using video data from a minimally structured physics laboratory classroom, we examine how student problematization (cognition about problems as problems) couples to their excitement. Analysis reveals two connections. First, problematization can set the stage for a future excited realization (an "Archimedean epiphany"). Second, a problem can itself be an excited realization (an "Asimovian epiphany"). We posit that, in both cases, students' attribution of value mediates the connection between cognition and affect: when students frame a certain kind of idea as valuable and then have an idea of that kind, they feel good about it. We conclude by discussing implications for design and facilitation.
\end{abstract}

\section{INTRODUCTION}

Scientific problems play a vital role in the construction of scientific knowledge [1]. Scientists think about problems daily in the laboratory, and recent research finds that students use similar cognitive processes in the classroom. Alongside experimental work in problem-posing [2], Phillips and colleagues have observed students "doing science" by working to define problems [1], and Engle \& Conant discussed the valuing of problems as a way to increase engagement [3]. This literature suggests that a theoretical focus on students' cognition about problems as problems can help us understand their learning. Accordingly, we borrow the term problematization to refer to the process of "identifying, articulating, and motivating the problem that needs solving" [1].

Both scientists and students have strong feelings about the problems they encounter, such as frustration or curiosity. These feelings are entangled with their cognition. Recent research names this entanglement epistemic affect and documents its importance to engagement [4] and personal epistemologies [5]. We believe a joint attention to problematization and affect is a productive lens through which to interpret this year's conference theme. Duckworth's exploration of "wonderful ideas," which she suggests are valuable in students' cognitive development, centers the role of children's "rais[ing] the right question for themselves" (problematization) because of the "real intellectual excitement" (positive epistemic affect) that can result [6]. In this work, we investigate the connection she proposes. How might problematization enable students to have ideas that they feel good about?

We ground this question in the framework of epistemic affect, with problematization as the cognitive domain of primary interest. In this paper we restrict our scope further to focus on affect that is epiphanic, such as excitement, joy, and relief. We ask, first, in what ways can the cognitive activity of students' problematization and the affective activity of their epiphanies be "complexly entangled" [4]? Second, what explains this coupling?

In answer to the first question, we argue for the existence of two different types of connection between problematization and epiphany. The first is that problematization can set the stage for ideas that provoke positive affect, just as Archimedes allegedly exclaimed "Eureka!" upon solving a problem. We call this type of cognitive-affective activity an Archimedean epiphany. The second type is that problems themselves can provoke positive affect, just as Asimov allegedly said, "The most exciting phrase in science is not 'Eureka!' (I found it!) but 'That's funny...' " [7]. We call this an Asimovian epiphany. These types are likely not dichotomous; we present both in the hope that through their contrast we may help illuminate the theoretical space that they occupy.

In answer to the second question, we propose a common mechanism linking problematization to positive affect in these two types of epiphany. Jaber \& Hammer [4] contend that students' (and scientists') emotions such as curiosity and frustration cause them to be engaged with science learning: their feelings "drive their inquiries" (emphasis ours) [4]. Inspired by this causative foundation, we raise the question of an earlier element of the chain of causation. Rather than discuss how students' epistemic affect can influence their engagement, we observe that their epistemic affect can be influenced by their valuing of certain inquiry-related achievements. We argue that value is a mediating factor between the ideas students have and their positive affect about those ideas. Specifically, when students frame a certain kind of idea as valuable and then have an idea of that kind, they feel good about it. Problematization, in turn, either coincides with the construction of value (in an Archimedean epiphany) or coincides with the idea (in an Asimovian epiphany).

Following the discussion of our methods, the paper presents two episodes from classroom video to illustrate the two types of epiphany and explicate the role of value as a mediating factor. We conclude by discussing some implications for course design and facilitation, including for laboratory courses specifically.

\section{METHODS}

This study emerged from a project to reform introductory physics laboratory courses at a large public Midwestern university. Students in the new lab collaborate with each other 
to design, perform, and report on their own experiments using an IOLab, a brick-sized cart equipped with sensors that can be connected wirelessly to plotting software and used for mechanics and electromagnetism experiments [8].

The data for this study comes from three laboratory sections of the algebra-based introductory mechanics course. We collected over 140 hours of classroom video for another project, from which we selected one 2.5-hour video of a class session for more open-ended analysis because students showed striking affective signs of engagement [9] that were exciting to watch [10]. In this class session, groups worked collaboratively on a task that asked them to design and perform two independent measurements of the coefficient of friction between their IOLab and a smooth wooden board.

To focus our analysis on the most relevant selections of the data, we used multiple cycles of analysis at decreasing grain sizes [11]. At each grain size, the first author developed representations of their interpretation such as content logs, diagrams, and transcripts $[9,11,12]$. These were shared with the second author and another collaborator, with whom they were refined and used to develop arguments.

We inferred students' problematization, positive affect, and assignment of value from their discourse. To infer problematization, we follow the literature $[1,13]$ by looking for schema and framing clues $[14,15]$. We do the same to infer ideas. For inferring affect, we rely on surface affective features, such as prosody, laughter, and gesture. For inferring value, we loosely use schema and framing theory. Future work should consider refining this method or switching to a method that can infer the assignment of value more directly.

This video featured a group of three students: Aliya (she/her), Connor (he/him), and Sal (he/him). All student names are pseudonyms, and pronouns are what they used for each other. We did not collect their pronouns or other demographic information, a choice that avoids potentially taxing self-disclosure but can be inaccurate $[5,16]$.

The final selection of data consisted of two episodes from this video. The first episode we present shows an Archimedean epiphany; the second, an Asimovian epiphany.

\section{DATA AND ANALYSIS}

\section{A. An Archimedean epiphany}

In this episode, each student identifies and motivates a need (i.e. problematizes) and displays positive affect when they satisfy that need. In other words, each student has an Archimedean epiphany, in which their cognition and affect are entangled: the cognitive work they do to assign value to the problem enables their positive affect about the solution.

During this episode, the group discusses the second of their two independent methods. The task is vague about what an "independent" method is. Consequently, the group works to articulate more clearly what gap their method must fill.

Their first method had used the force probe. In the excerpt below, Sal begins by wondering aloud whether it's possible to avoid using the force probe for their second method.

Sal: I honestly think there's a way to solve this without.... I'm going to try.

Aliya: Without doin'-

Connor: With just acceleration?

Sal: I think so.

Connor: I dunno man. Sounds sketch.

Sal: Yeah, it does. (laughs)

Connor: (laughs) (pause) 'Cause like the net force is involved with forces in two different directions. (points across body with both arms in different directions) So I feel like you need the one direction to be known for us to figure out the unknown frictional force.

Sal: Yeah, that's true. So I'm just gonna try something, to see-

Connor: Yeah, I'm not gonna crush your dreams. I'd be mad impressed if there were a way though.

The cognitive activity in this excerpt is problematization: the group discusses whether an accelerometer-only measurement method is possible (identifying and articulating the problem), and whether it is valuable (motivating it). Sal, working with equations in his notebook, wonders if it is possible to "solve" those equations using just acceleration as an independent variable. He announces that he will try it, implying that the task has value (hence Connor's reference to his "dreams"). Connor apparently believes it is impossible, or nearly so; consequently, he explicitly assigns value to accomplishing such a feat, stating he would be "mad impressed." Similarly, a few minutes after the transcribed portion, he describes not using the force probe as a sign of "great scientific prowess." Connor and Sal emerge having constructed a problem and assigned value to finding a solution.

Later, both Connor and Sal realize how to solve the problem, and both display positive affect about their realizations. Connor's positive affect is most pronounced in a moment of retelling. After Connor shares his idea, Sal changes his mind and begins doubting that any method without the force probe will work. Connor responds:

Connor: (laughing) Ooh, see, that's what I was saying, and you were like, nah, I think we can figure it out. As you were starting to get to the point where it's like, nah, it's not possible, I'm like, (low and breathily) Wait. It's possible.

Connor's version of events frames him as having a dawning realization, one about which he is excited and confident. His idea perfectly solves the problem he has posed, one to which he has ascribed value. We find it plausible that the positive affect arises out of this perfect fit. Connor assigns value to solving the problem that he identified, so figuring it out provokes excitement and pride.

We see similar displays of positive affect in each of the group members when they solve a problem that they posed 
and motivated. For Sal this happens much later in the video, when he finally realizes how Connor's method works mathematically, which was his main concern during problematization, and comments, "Okay, so that's why it comes together." He finally solves the precise problem that he had identified and motivated; the value of this problem mediates his expression of positive affect (relief).

Aliya too identifies a different problem. She believes that the group does not yet have a second independent method at all. Earlier, after clarifying the task with Connor, she exclaims that they need to come up with "A whole, separate [method]? Oh, whoa." The interjection "whoa" suggests that such an invention would be challenging and, because the group needs it for the assignment, a valuable achievement. Later, we see Aliya achieve this very thing. She performs an excited series of gestural bids to interrupt a conversation between Connor and Sal, including a "mind blown" gesture, and then offers a very different idea for a measurement method. When Connor cautiously rejects her idea, she restates the need she identified with dramatic intonational emphasis: "What would we use instead?" The value she sees in this cognitive achievement explains the excitement she displays through her bids.

The epiphanies that Aliya, Connor, and Sal have look like Archimedean epiphanies: they specify a valuable gap in the puzzle that needs to be filled, and then-"Eureka!"- they find a puzzle piece that fits the gap. The cognitive work of assigning value to filling the gap enables them to experience positive affect when they find a suitable solution.

\section{B. An Asimovian epiphany}

Sometimes positive affect is a response to solving a problem. Other times, the positive affect is not a response to a solution at all, but in fact to a new problem: less a "Eureka!" than an excited "That's funny...." In this episode, we see our group encounter an unexpected problem-their IOLab is miscalibrated - and react to it with excitement and joy. Although part of their excitement is about solving an existing problem, here we focus on the significant part of their excitement that is about the discovery of the new problem.

Whereas in an Archimedean epiphany the positive affect is a delayed response to the cognitive work of problematization, in an Asimovian epiphany the two are simultaneous. Value still plays a mediating role. In this episode, the group displays positive affect because the problem they encounter constitutes a "discovery" of new knowledge concerning their experimental setup. The tacit cultural value of scientific discovery, which predated their problematization and is primed by their discussion of being "legit [scientists]," enables them to feel excitement about their problematization itself.

When this episode occurs, the group is attempting to pull the IOLab at constant velocity so that they can measure the coefficient of kinetic friction with the force probe. Despite Sal's careful attempts to pull the IOLab without acceleration, the accelerometer plot persistently reads a nonzero value. The group sits pensively, when suddenly Connor has a question.

Connor: Question. If you just, run the IOLab without pulling it? And just like, just record.

Aliya: See what it does?

Sal: (raises index finger) Okay, I see, I see what you mean.

Connor: Yeah let's see, let's see if it's exactly zero.

Sal: (manipulates trackpad of laptop)

Connor: (leans toward the screen to see the results) Ohhh, it's totally not...!

Sal: Oh, wow.

Connor: It-Ohhhhh! (rolls backward on chair while pointing repeatedly at the screen with alternating index fingers while Aliya and Sal smile and laugh) (to Sal) You were totally doing it perfectly those first two trials.

Sal: Okay. So, yeah I think we're pretty good.

This excerpt shows the group having an epiphany: the accelerometer is wrong! The acceleration of a motionless IOLab is clearly zero, but the accelerometer is reading a nonzero value. The group feels positively about this realization; complementing Connor's exclamation, Sal and Aliya smile and laugh. This positive affect accompanies the revelation of a scientific problem: the accelerometer reads the wrong value. We are accustomed to problems being received with frustration [4]; this problem is received with excitement. Why?

One contributing factor is that the appearance of this problem solves their previous, harder problem. The group assumed that the accelerometer was reading the correct value, and consequently tried without avail to pull the IOLab at constant velocity. The knowledge that the accelerometer was reading the incorrect value allows them to recoup their losses; consequently, they feel good about it. In this explanation, the positive affect responds to what their realization solved. This component of their epiphany is Archimedean.

Another contributing factor, which is not Archimedean, becomes clear later in the episode: they conceive of their realization that the accelerometer is miscalibrated as a discovery. In this explanation, their positive affect is about the identification of the problem itself. The excerpt below reveals this Asimovian component.

Just as Sal finishes saying "we're pretty good," the TA walks up to their table and looks at a small whiteboard sitting next to Aliya, on which is written "We are legit." Aliya wrote it following the group's exchange with another TA that to her sounded "so legit."

TA: (reads whiteboard) "We are legit." You are legit.

Aliya: (laughing) Forgot I wrote that.

Connor: We just made a major discovery.

TA: I'd love to hear it!

Aliya: That was like great timing.

Connor: (tells the story of the miscalibration discovery while Aliya and Sal face the TA) ... and we realized that [the accelerometer is] not exactly at zero, ...

TA: Oh! Why do you think that is? 
Connor and Sal immediately suggest recalibrating the sensor. Aliya wonders if the table's tilt is causing the problem.

This excerpt shows us that the group's excitement is about more than just solving their earlier problem. Connor's announcement of a "discovery" attributes value to their realization, with the tacit support of Aliya and Sal, whose gaze positions Connor as a spokesperson. Aliya's comment that calling the group legit is "great timing" constructs the group as great scientists on the evidence of their recent discovery. And yet the discovery, what Connor says they "realized," is actually a problem. Indeed, all three of them have ideas about what still needs to be fixed: the calibration or the tilt of the table. The group's excitement is not just about solving their earlier problem; it is about identifying a subtle new one.

Tacit cultural values concerning science triggered by the group's discourse explain their excitement. Aliya's construction of the group as "legit" frames their activity, positively, as not merely completing an assignment, but doing science. Connor's use of the term "discovery" connotes the value of revising old understandings-including, in this case, of the problem. The group's attribution of value to scientific discovery enables them to experience positive affect about the cognitive work they do to refine the problem they are solving.

\section{DISCUSSION}

We have seen the cognitive work of problematization linked with positive affect in two different ways: first when students find solutions, and second whent they construe the problem itself as a discovery. This contributes to the growing argument for combining affective and cognitive perspectives on learning. Specifically, we observe a mechanism by which students' discursive cognitive activity influences their affective displays: when the group's discourse frames a problem or idea meeting certain conditions as valuable, it enables students to feel positively about the problem or idea.
Bringing epistemic affect into the classroom, such as the epiphanies we observed in this paper, can encourage engagement and help students "learn to feel like a scientist" [4]. Based on this study, we have several recommendations for doing so. First, both curriculum and instruction matter. We saw here that the underspecified task was the inspiration for students' problematization, and we also saw that an encouraging TA contributed to the group's explication of the value of their discovery. Second, methods that enable students to discuss value as it pertains to their inquiry may invite displays of epistemic affect into the classroom. Curriculum materials and instructional methods that refocus students' attention on problems as problems are promising candidates because of the role that motivation plays in problematization processes.

Designing for epistemic affect can support other goals as well. In addition to playing a role in student engagement [4], it may be connected to students' sense of ownership over their inquiry. Dounas-Frazer and colleagues observed that student groups' ownership of their physics laboratory projects were associated with "feelings of...confidence, enjoyment, and frustration [that] varied dynamically" [17]. They made special note of the role played by "momentary successes [which] contributed to students' increased enjoyment of the project, and... their confidence" [17]_epiphanies. We advocate that educators involved in physics laboratory courses consider using problematization and discussion of value to bolster students' outcomes via their epistemic affect.

\section{ACKNOWLEDGMENTS}

Thanks to Stina Krist for offering her experience in qualitative video analysis and her insights during analysis and writing; to Katie Ansell, Jason Morphew, and our referees for their feedback on the manuscript; to Bill Evans for teaching; and to our students for reminding us how exciting learning can be. This work was supported in part by the NSF through grant 244 NSF DUE 17-12467.
[1] A. M. Phillips, J. Watkins, and D. Hammer, Phys. Rev. Phys. Educ. Res. 13, 020107 (2017).

[2] J. P. Mestre, J. App. Dev. Psych. 23, 9 (2002).

[3] R. A. Engle and F. R. Conant, Cog. Instr. 20, 399 (2002).

[4] L. Z. Jaber and D. Hammer, Sci. Educ. 100, 189 (2015).

[5] A. Gupta, A. Elby, and B. A. Danielak, Phys. Rev. Phys. Educ. Res. 14, 010129 (2018).

[6] E. Duckworth, Harv. Ed. Rev. 42, 217 (1972).

[7] O'Toole, G, on Quote Investigator, https://quoteinvestigator. com/2015/03/02/eureka-funny/. Retrieved 7/5/2018.

[8] M. A. Selen, Bullet. Am. Phys. Soc. 58, http://meetings.aps. org/Meeting/APR13/Session/C7.3. Retrieved 7/6/2018.

[9] R. A. Engle, F. R. Conant, and J. G. Greeno, in ibid., pp. 239254.

[10] M. T. Hayes, in Video Research in the Learning Sciences, edited by R. Goldman, R. Pea, B. Barron, and S. J. Derry (2007), pp. 67-76.
[11] B. Barron, in ibid., pp. 159-187.

[12] S. J. Derry, R. D. Pea, B. Barron, R. A. Engle, F. Erickson, R. Goldman, R. Hall, T. Koschmann, J. L. Lemke, M. G. Sherin, and B. L. Sherin, J. Learn. Sci. 19, 3 (2010).

[13] J. Watkins, D. Hammer, J. Radoff, L. Z. Jaber, and A. M. Phillips, J. of Res. in Sci. Teach. 55, 573 (2017).

[14] D. Tannen, in Framing in Discourse, edited by D. Tannen (Oxford University Press, 1993), pp. 14-56.

[15] D. Tannen and C. Wallat, in ibid., pp. 57-76.

[16] B. Zamarripa Roman, J. J. Chini, A. Little, C. Turpen, A. Traxler, J. Doyle, workshop at Phys. Ed. Res. Conf. 2017, https://www.compadre.org/per/perc/2017/Detail.cfm?ID= 6778. Retrieved 7/6/2018.

[17] D. R. Dounas-Frazer, J. T. Stanley, H. J. Lewandowski, Phys. Rev. Phys. Educ. Res. 13, 020136 (2017). 